\title{
Energy Saving and Carbon Reduction by Tree Planting at Multifamily Residential Sites in a City, Korea
}

\author{
Hyun-Kil Jo', Jin-Young Kim² \\ ${ }^{1}$ Department of Ecological Landscape Architecture Design, Kangwon National University \\ Chuncheon 24341, Republic of Korea \\ jhk@kangwon.ac.kr \\ ${ }^{2}$ Department of Landscape Architecture, Graduate School, Kangwon National University \\ Chuncheon 24341, Republic of Korea \\ jykim84@kangwon.ac.kr
}

\section{Extended Abstract}

Serious concern about climate change has increased interest in the potential for urban trees to help reduce the level of atmospheric carbon. Trees planted in multifamily residential sites (MRS) can reduce atmospheric carbon in two ways: directly sequestering the carbon through photosynthesis (direct carbon reduction) and avoiding carbon emissions through building energy savings (indirect carbon reduction). Much research has been conducted on carbon reduction effects by urban trees, but information is limited on indirect carbon reduction by residential trees $[1,2]$. The purpose of this study was to quantify energy saving and carbon reduction by tree planting and to suggest sustainable landscape design techniques for MRSs in Chuncheon, a capital city of Gangwon province in the middle region of Korea.

Data on tree planting and building distribution were collected in MRSs which were chosen using a stratified sampling method on aerial photographs with a scale 1:1,000. Eight straight lines radiating from the center of the study city were drawn in eight different directions, and subsequently circles were drawn $10 \mathrm{~cm}$ apart. This study sampled a total of $35 \mathrm{MRSs}$ in which the circles and lines coincided, and inventoried all the trees planted within the boundary of each MRS. This sample size was a compromise between the competing concerns for the reliability of data and the availability of expense. Annual direct carbon reduction by residential trees was quantified using carbon uptake models by tree species and size [3-8]. Annual indirect carbon reduction was computed applying an average carbon estimate per unit conditioned floor area for multifamily buildings in the study city $[9,10]$. These data were used to generate annual direct and indirect carbon reduction per unit area by residential trees.

Mean tree density and cover in the study MRSs were 7.2 trees $/ 100 \mathrm{~m}^{2}$ and $17.7 \%$, respectively. Annual direct carbon reduction per unit area averaged approximately $1.2 \mathrm{t} / \mathrm{ha} / \mathrm{yr}$. Annual indirect carbon reduction averaged about $4.3 \mathrm{t} / \mathrm{ha} / \mathrm{yr}$, as associated with effects of residential trees on shading, evapotranspiration, and windspeed reduction. Tree planting at MRSs in the study city annually saved cooling energy by $1,199 \mathrm{MWh} / \mathrm{yr}$ and heating energy by $56,655 \mathrm{GJ} / \mathrm{yr}$. Total annual direct and indirect carbon reduction were about 1,523 t/yr. This carbon reduction equaled $6.2 \%$ of total annual carbon emissions from electricity consumption of multifamily buildings in the study city. Thus, residential trees played a significant role in reducing the atmospheric carbon concentration. Desirable design techniques including planting and building layout were explored to enhance effects of building energy savings and carbon reduction. This study is expected to contribute to sharing the role and technique of sustainable residential design for the effects.

\section{Acknowledgement}

This study was carried out with the support of the 'R\&D Program for Forest Science Technology (Project No. 2017043 B10-1819-BB01)’ provided by the Korea Forest Service (Korea Forestry Promotion Institute).

\section{References}

[1] E. G. McPherson, “Atmospheric carbon dioxide reduction by Sacramento's urban forest,” J. Arboriculture, vol. 24, no. 4, pp. 215-223, 1998. 
[2] H. K. Jo and E. G. McPherson, "Indirect carbon reduction by residential vegetation and planting strategies in Chicago, USA,” J. Environ. Manag., vol. 61, pp. 165-177, 2001.

[3] H. K. Jo and D. H. Cho, "Annual $\mathrm{CO}_{2}$ uptake by urban popular landscape tree species," J. Korean Inst. Landsc. Archit., vol. 26, no. 2, pp. 38-53, 1998.

[4] H. K. Jo, "Carbon uptake and emissions in urban landscape, and the role of urban greenspace for several cities in Kangwon Province," J. Korean Inst. Landsc. Archit., vol. 27, no. 1, pp. 39-53, 1999.

[5] H. K. Jo and T. W. Anh, "Annual $\mathrm{CO}_{2}$ uptake and atmospheric purification by urban coniferous trees - for Pinus densiflora and Pinus koraiensi," Korean J. Environ. Ecol., vol. 15, no. 2, pp. 118-124, 2001.

[6] H. K. Jo and T. W. Anh, "Carbon storage and uptake by deciduous tree species for urban landscape," J. Korean Inst. Landsc. Archit., vol. 40, no. 5, pp. 160-168, 2012.

[7] H. K. Jo, J. Y. Kim, and H. M. Park, "Carbon storage and uptake by evergreen trees for urban landscape - for Pinus densiflora and Pinus koraiensis," Korean J. Environ. Ecol., vol. 27, no. 5, pp. 571-578, 2013.

[8] H. K. Jo, J. Y. Kim, and H. M. Park, "Carbon reduction effects of urban landscape trees and development of quantitative models - for five native species," J. Korean Inst. Landsc. Archit., vol. 42, no. 5, pp. 13-21, 2014.

[9] H. K. Jo, G. S. Han, and O. H. Seo, "Function of home energy savings and carbon emission reduction by urban vegetation - case of Chuncheon," J. Korean Inst. Landsc. Archit., vol. 26, no. 3, pp. 104-117, 1998.

[10] H. K. Jo and T. W. Anh, "Exploration of a proper residential landscape for energy saving and carbon reduction," $J$. Des. \& Arts, vol. 2, pp. 77-89, 2000. 